\title{
PHOTOBIOMODULATION THERAPY USED IN TREATMENT OF ORAL HEMATOMA WITH 940NM DIODE LASER - A CASE REPORT
}

\author{
Dr.Vidyaa Hari Iyer
}

General Dental Practitioner, Chennai, Tamil Nadu , India

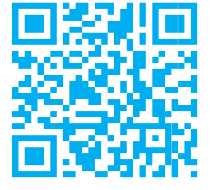

DOI: 10.37841/jidam_2021_V8_I3_08

Address for Correspondence

Dr. Vidyaa Hari Iyer,

Director and Private Practitioner,

Dr.Vidyaa's Smile Dental Clinic,

No: 30/34, Ramanujam Street, TTDC Temple,

T.Nagar, Chennai,Tamil Nadu-600017, India

Email id: drvidyaacrown@gmail.com

Received: 12.08.2021 First Published: 11.09.2021

Accepted: 09.09.2021

Published: 27.9.2021

\section{ABSTRACT}

Oral Hematoma generally occurs in the oral cavity due to sharp teeth by accidental biting of the cheeks, lips, tongue, oral mucosa or any soft tissues. These vascular lesions sometimes could have a feeder artery or blood vessel which could hinder the treatment protocol. Laser tissue interaction is basically dependent on the wavelength of laser used and the chromospheres within the host tissue which absorbs the laser light. Diode lasers have an affinity for blood, hemoglobin, haemosiderin and melanin predominantly as their chromophores. Hence shorter wavelength lasers such as Diode work very well in treatment of oral hematomas. Low level laser therapy or photobiomodulation works on the phenomena of light photons that are absorbed by cytochromes and porphyrins in the mitochondria of the cell thereby increasing cell respiration and transcription bringing about desired laser tissue interaction. This article highlights the use of diode lasers in the treatment of such oral hematomas.

Key words: Low level laser therapy, photobiomodulation, oral haematoma, bloodless, painless, laser therapy, sutureless, laser healing, Diode laser, 940nm Diode laser, phototherapy, vascular lesions 
Vidyaa Hari Iyer et al: Photobiomodulation Therapy Used In Treatment of Oralhematoma

\section{INTRODUCTION:}

Haemangiomas are generally benign and selfinvoluting swelling of the endothelial cells that line the blood vessels and are filled with blood. ${ }^{1}$ Oral haemangiomas evolve due to chronic biting, accidental injury, eccentric jaw movements of mandible, nick by a drill or knife during any surgical procedure, irritation by sharp objects, ill-fitting dentures or teeth pinching on the soft tissues of the oral cavity, lips, cheeks and tongue. ${ }^{2}$ There is accumulation of blood cells and fluids within the soft tissue due to breach in the blood vessel wall thereby causing enlargement of the tissue over it, giving rise to the hematomas. ${ }^{3}$ These hemorrhagic lesions are usually painless, uncomfortable and cause anxiety in patients. These lesions resemble a bulge caused due to an internal bruise. Most of these haematomas are small in size and selfresolve over a period of time. The healing period may go on for few days, sometimes extending into few weeks too. ${ }^{4}$ Many a times in large oral haematomas the lesion remains reddish in colour and looks enlarged which can impact normal eating habits, speech, swallowing and affects the confidence of the patient as the patient is always conscious of the area meddling with his tongue or finger on the site. ${ }^{5}$ These lesions are traumatic and not infectious hence painkillers or antibiotics seldom aid in the treatment modality. When these lesions occur in areas of aesthetic concern the patients insist on immediate intervention with guaranteed results. ${ }^{4}$

\section{LASER EQUIPMENT}

A 940nm wavelength diode laser (Ezlase; Biolase, USA) was used for Low Level Laser Therapeutic procedure for the treatment of oral haematoma. Diode lasers are surgical in nature and are classified as Class IV type according to Laser safety protocol. Hence all laser safety precautions have to be adhered to. ${ }^{6}$ Wearing protective wavelength specific eyewear of optical density of 5 and above is the norm, using plastic or non-metallic instruments to reduce reflective surfaces within the operatory, placement of laser safety sign boards, reducing the traffic within the operatory, prevention or controlling any hazards during operation is controlled and monitored by the Laser Safety Officer. ${ }^{2}$ Proper documentation of the parameters in clinical patient records also aid in prevention of medico legal issues later. ${ }^{7}$ A de-focussed continuous emission mode was used with no tips to give a scattering laser tissue effect on the host chromophores. ${ }^{8}$

\section{PROCEDURE - CASE REPORT}

A 60-year-old female patient had visited Dr.Vidyaa's Smile Dental Clinic with complaint of a blood clot in right side of the cheek. The general health and systemic condition of the patient was evaluated with proper history. Patient is a known hypertensive and under medication. Patient had undergone hysterectomy a decade back and was not on any hormonal replacement therapy.

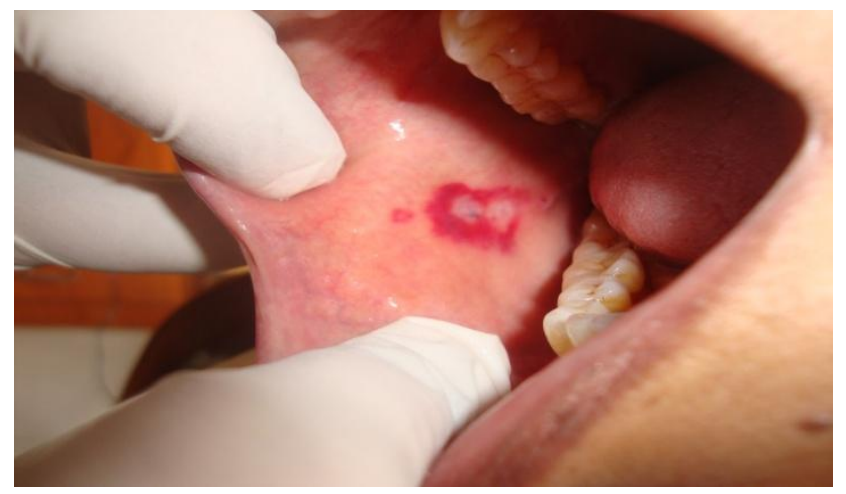

Fig 1: An oral haematoma lesion in the right cheek of mouth

On clinical examination, the lesion was flat and bright red in colour, painless measuring around $3 \times 2 \mathrm{~cm}$ in dimension at the centre of the right buccal mucosa towards the occlusal inter-digitation of both the jaws. The lesion had marks of sharp tooth imprint on it suggestive of accidental sharp tooth bite on the cheek(Fig 1). The patient was otherwise asymptomatic but was concerned as the lesion was present for over 3 days with no signs of regression. She insisted on immediate treatment protocol and needed a permanent solution to the concern. On digital examination of both maxillary and mandibular teeth on the right side, they had sharp cusp tips confirmatory to the insult caused to the surrounding tissues. Conventional treatment protocol generally involves giving anesthesia near the lesion site which involves pain, further excision of the lesion and then suturing of the surgical site is carried out. The patient being a hypertensive for over 2 decades was on hypertensive medications and blood thinners. This also could be contributory factor for the haemangioma along with local dental factors. The patient was explained about various treatment interventions. The patient preferred the laser treatment protocol due to the advantages cited and informed consent was taken. 


\section{Vidyaa Hari Iyer et al: Photobiomodulation Therapy Used In Treatment of Oralhematoma}

The patient was made comfortable in the dental chair and all laser safety protocol was followed. Laser safety glasses was given to the patient to wear and was instructed not to the remove them till the procedure was completed. Enameloplasty was suggested and carried on all sharp teeth on the right side till the patient was comfortable and had no symptoms of discomfort. As the patient was a little apprehensive, topical anaesthetic gel (Procaine contains Lidocaine $8 \%$, Dibucaine $0.8 \%$ in a flavoured aqueous base) was applied at the surgical site. The 940nm wavelength Diode laser was used with conventional handpiece at $0.5 \mathrm{~W}$ continuous (Fig 2) non-contact mode. (Fig 3) The lesion was ablated with the laser with one cycle of laser energy. Low Level Laser Therapy [LLLT] or photobiomodulation was carried out on the concerned site to aid in positive healing mechanism.(Fig 4)

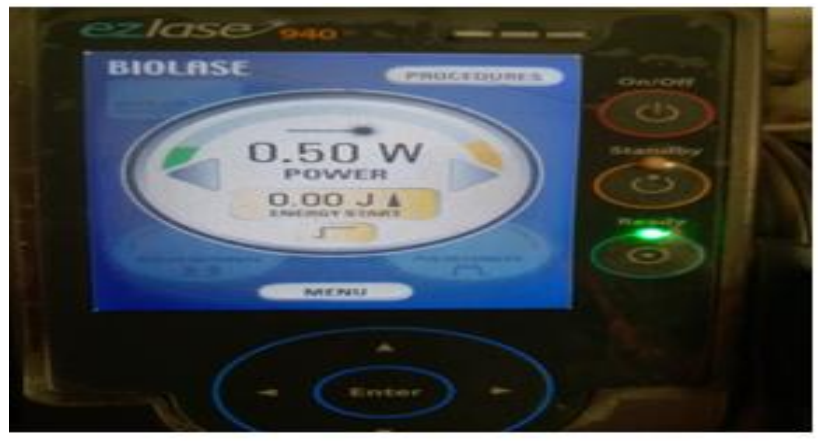

Fig 2 : Low Level Laser Therapy parameters 0.5 W continuous emission mode

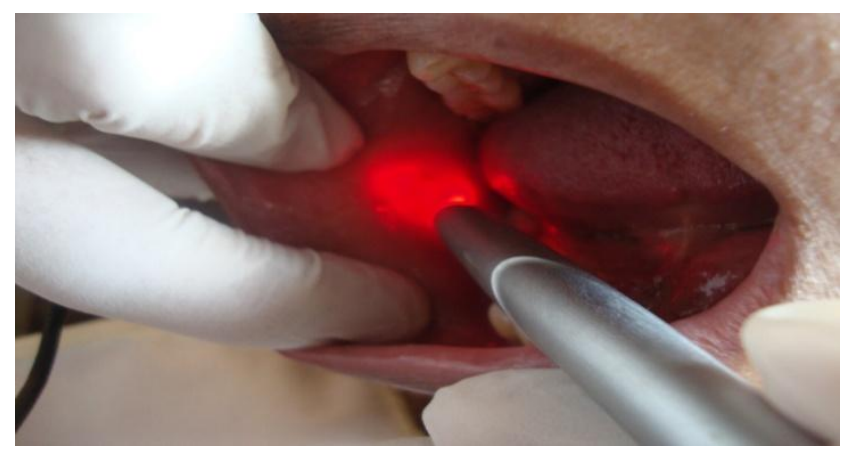

Fig 3: Low level laser therapy done with 940nm Diode laser in non-contact defocussed mode

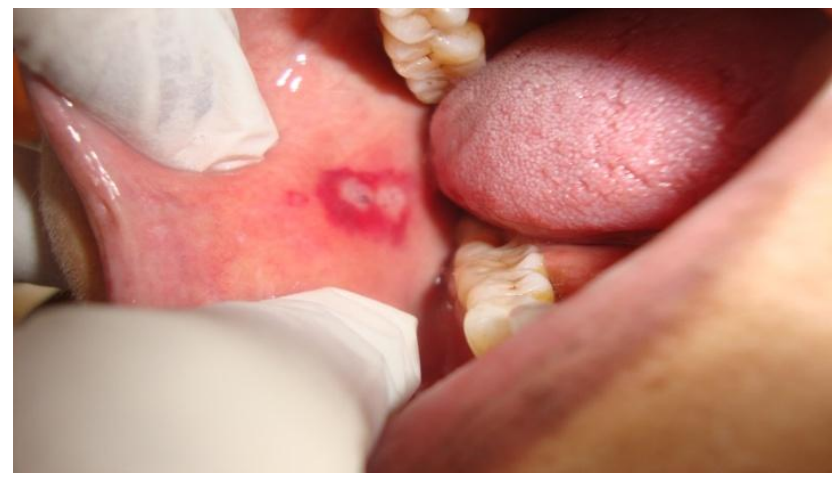

Fig 4: Immediate post-operative view after Laser application

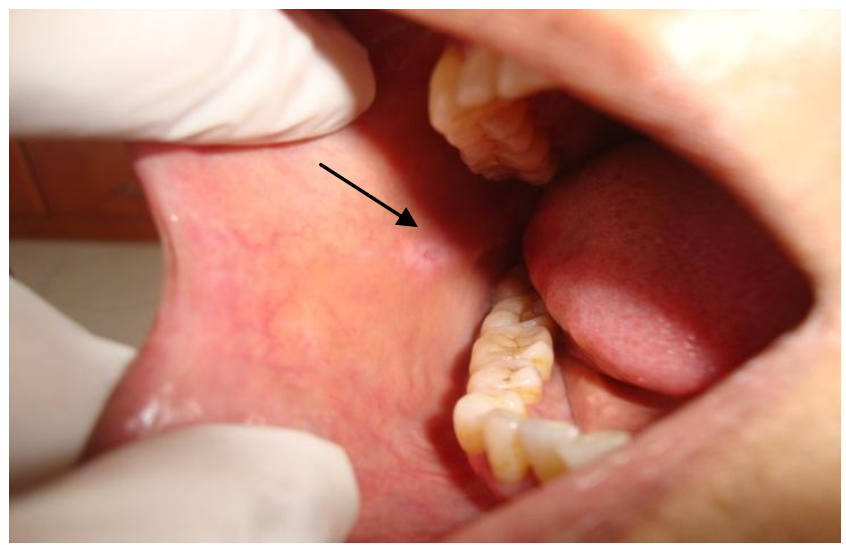

Fig 5: 24 hour's post-operative view with the oral haemangioma lesion treated using lasers following Arndt Schultz law, Enameloplasty done on sharp teeth and imprint of the sharp teeth still seen in the healing site (arrow).

The patient was instructed to have cold soft diet for a day with cold ice pack application for first 24 hours. Brushing was suggested in the normal daily twice format with a soft bristle brush to avoid any further injury to the site. Warm saline water gargling was also instructed in case the patient had any soreness at the treatment site after 24 hours. The patient was recalled after 24 hours to check the healing by lasers. (Fig 5) Photographs were taken to record the case at all levels of intervention. The patient was extremely comfortable during the healing stage. She had not taken any medications and was able to resume her routine daily activities with ease. The patient continued her routine medication for hypertension.

\section{MECHANISM OF ACTION}

Endre Mester, a Hungarian physician and surgeon has been instrumental and credited with the discovery of the biological effects and biochemical advantages of Laser 
Vidyaa Hari Iyer et al: Photobiomodulation Therapy Used In Treatment of Oralhematoma

biostimulation $^{1}$ since 1960 s or LLLT as it is called now. ${ }^{9}$ He emphasized that $\mathrm{LLLT}^{2}$ has positive effects to accelerate wound healing, treat pain and myalgia, oral mucositis ${ }^{3}$, chronic periodontitis ${ }^{4}$, peri-implantitis, tooth hypersensitivity, accelerated orthodontic tooth movement, ulcer healing, tempero-mandibular joint pain and also used in sports medicine for pain relief.

A lot of research has thrown light in the biochemical effects of LLLT $^{5}$ and its advantages in medical science. LLLT uses light energy in the form of photons to produce cellular responses ${ }^{6,7}$. Light photons are absorbed by cytochromes and porphyrins in the mitochondria of the cell. It has been proposed that three things occur:-

- Stimulation of ATP (Adenosine Triphosphate) synthesis by activation of the electron transport chain.

- Transient stimulation of Reactive Oxygen Species (ROS), which increases the conversion of ADP to ATP.

- A temporary release of Nitric Oxide (NO) from its binding site on Cytochrome-C Oxidase, which results in an increase in cell respiration and transcription. ${ }^{10}$

\section{DISCUSSION}

Low Level Laser Therapy [LLLT] in low doses is bio stimulatory in nature and aids in healing. The chromophores in the host tissue is blood and more the chromophore, lesser laser parameters can be used. The skin over the haematoma and blood absorbs the laser energy and then gets dissolved. Photobiomodulation is a physiotherapeutic application of low power lasers or soft lasers ${ }^{9}$ and is gaining its popularity now in dentistry for pain relief and bio-stimulation of tissues. ${ }^{10}$ High power lasers or hard lasers in dentistry are generally used in tissue cutting, selective cavity cutting, excision of soft tissues etc. ${ }^{11}$ Low level laser therapy is widely used in dentistry for ulcer banding, myalgia, wound healing, gagging reflex, muscle pain, and temperomandibular joint pain relief and as an additive adjunct after laser procedures such as depigmentation, frenectomies, tissue excisions, post extraction sites etc. ${ }^{12,13}$

LLLT is a safe, effective and alternate form of therapy for acute and chronic conditions precipitating pain and its relief. LLLT uses laser light at very low powers near the infrared light of the electromagnetic spectrum. It promotes healing, prevents tissue damage, decreases pain, and reduces inflammation. Usually during any stressful conditions in the cell, the mitochondria produce Nitric oxide and free radicals. The oxygen within the cells gets displaced due to the release of Nitric oxide leading to cell inflammation and further cell death. Low doses of laser energy from shorter wavelength lasers such as Diode when released on such stressed areas of the body or cell, the tissues absorb the laser energy and increases cell respiration. The increase in oxygen inflow helps in tissue oxygenation and brings about breakdown of the Nitric oxide, thereby increasing mitochondria function, cell metabolism, cell proliferation, cell migration, increases release of growth factors and inflammatory mediators and finally restoring cell health.

LLLT accelerates wound healing and also reduces pain by stimulating oxidative phosphorylation in mitochondria, thereby modulating the inflammatory responses. LLLT positively influences the biologic function of all the cells which has beneficial effects on tissue healing. Arndt Schultz law implies that laser energy in small low doses stimulates the tissues and in heavy large doses is detrimental to the healing site. ${ }^{9}$ So, low doses of laser energy have a therapeutic effect without any collateral tissue damage on the peri-healing tissue site. LLLT has gained slowly acceptance and is now widely used as an adjunctive modality of treatment. ${ }^{12}$

\section{CONCLUSION}

Low level laser therapy has been proven beyond doubt that it has innumerable positive effects on every cell organelle and is a treatment of choice now-a-days. Minimally invasive conservative comprehensive dental care is the need of the hour. Lasers are undoubtedly the answer for patients who are seeking such treatment advantages over conventional modalities.

\section{FINANCIAL SUPPORT AND SPONSORSHIP}

Nil

\section{CONFLICTS OF INTEREST}

There are no conflicts of interest.

\section{REFERENCES}

1. Karu T I: Photobiological fundamentals of lowpower laser therapy. IEEE J Quant Electron 1987; QE-2 3: 1703-1717.

2. Laakso E L, Richardson C R, Cramond T. Factors affecting low level therapy. Aust J Physiol 1993; 39:95-99.

3. Oberoi S, Zamperlini-Netto G, Beyene J, Treister NS, Sung L. "Effect of prophylactic low level laser therapy on oral mucositis: a systematic review and meta-analysis". PLOS One 2014; 9 (9):e107418. 
Vidyaa Hari Iyer et al: Photobiomodulation Therapy Used In Treatment of Oralhematoma

4. Cobb C. M. "Lasers in Periodontics: A Review of the Literature". Journal of Periodontology 2006; 77 (4): 545-564.

5. S.Parker. Low - level laser use in dentistry. British Dental Journal 2007; 202(3):131-138.

6. Karu T I. Molecular mechanism of the therapeutic effect of low-intensity laser radiation. Lasers Life Sci 1988;2: 53-74,

7. Prindeze Nicholas J, Moffatt Lauren T Shupp, Jeffrey W. "Mechanisms of action for light therapy: a review of molecular interactions". Experimental Biology and Medicine 2012; 237 (11): 1241-1248.

8. Chung Hoon Dai, Tianhong, Sharma Sulbha K, Huang Ying-Ying, Carroll James D, Hamblin Michael R."The Nuts and Bolts of Low-level Laser (Light) Therapy". Annals of Biomedical Engineering 2012; 40 (2): 516-533.
9. Dr.Gayatri B.Aher, Dr.Sameer Jadhav, Dr.Naresh Thukral, Dr.Vivek Hegde. Soft Lasers in Dentistry. Journal of Laser Dentistry 2009; 3(1); 33-38.

10. Walsh L J: The current status of Low Level Laser Therapy in dentistry. Soft tissue applications. Aust Dent J 1997; 42:247-254.

11. Da Silva J. P, Da Silva M. A, Almeida A. P. F, Junior I. L, Matos A. P. "Laser Therapy in the Tissue Repair Process: A Literature Review". Photomedicine and Laser Surgery 2010; 28 (1): 17-21.

12. Chen J, Huang Z, Ge M Gao M. "Efficacy of lowlevel laser therapy in the treatment of TMDs: a meta-analysis of 14 randomised controlled trials". Journal of Oral Rehabilitation 2015; 42 (4):291-299.

13. Bezuur N.J, Hansson T.L. The effects of therapeutic laser treatment in patient with cranomandibular disorders. J Cranomandib Disorders 1998; 2: 83-86. 